\title{
Well-Being and General Anxiety Among University of Michigan Dental Students
}

\author{
Mark Ash", DDS and Elisabeta $\operatorname{Karl}^{\dagger}$, DDS, MS, PhD
}

\section{Background}

Anxiety is one of the most prevalent mental health conditions, affecting approximately 1 in 9 people worldwide. More specifically, dental students have been considered vulnerable to anxiety despite the fact that dental students have also reported high levels of well-being. Therefore, we hypothesize that University of Michigan School of Dentistry (UMSOD) dental students pose high levels of well-being but suffer from anxiety. Our objective is to measure anxiety and well-being levels among UMSOD dental students for 2 consecutive academic years.

\section{Methods}

Dental students $(\mathrm{N}=609)$ were surveyed for well-being and general anxiety levels. To assess well-being and anxiety levels we used the World Health Organization-Five Well-Being Index (WHO-5) questionnaire and the General Anxiety Disorder 7-item (GAD-7) scale, respectively. Surveys were sent through Qualtrics. For statistical analysis, chi-square and t test were used at $\mathrm{p}<0.05$.

\section{Results}

The mean well-being score among dental students was $12.26(\mathrm{SD}=1.14)$. In the first survey moment for anxiety, which coincided with the week before the spring break in 2017 , approximately $39 \%$ of the respondents $(n=255)$ scored 10 or higher on the GAD-7, which means moderate anxiety. In the second survey moment, the week after the spring break week in 2017, we found a slight but not significant reduction in anxiety levels, with approximately $32 \%$ of the responses $(n=109)$ of the dental students scoring 10 or higher on the GAD-7. Incoming first-year dental students before starting the dental school program presented well-being mean of 18 ( $\mathrm{SD}=0.60)$. Only $13 \%$ of incoming firstyear dental students scored 10 or higher on anxiety before starting the school program. By the fall term, the well-being mean among incoming first-year dental students dropped to 13.29 ( $\mathrm{SD}=1.32$ ), and $22 \%$ of the incoming first-year dental students scored 10 or higher in the GAD-7.

\footnotetext{
"University of Michigan Dental School, mtash@umich.edu

†University of Michigan Dental School, ekarlz@umich.edu (D) https://orcid.org/0000-0002-3026-0167
}

doi: $10.3998 / \mathrm{mjm} .1434$

Conflicts of interest:

The authors have no conflicts of interest to disclose 


\section{Conclusions}

University of Michigan School of Dentistry dental students posed poor well-being and moderate anxiety. Incoming first-year dental students posed higher well-being and lower anxiety levels before starting the dental education program. However, as the academic year developed, incoming first-year dental students suffered a decrease in well-being and an increase in anxiety levels. Our study indicates a trend of poor well-being and high anxiety among UMSOD dental students.

\section{Keywords}

anxiety $\bullet$ dental $\bullet$ students

\section{Introduction}

Anxiety disorders, or often simply called anxiety, are the most prevalent mental health condition, affecting approximately 1 in 9 people worldwide. ${ }^{1}$ Anxiety can be characterized by excessive, persistent, or unrealistic worry about daily tasks, events, and routines. ${ }^{1,2}$ More specifically, anxiety highly affects dental students because dentistry has been considered as one of the most challenging, demanding, and stressful fields of study. ${ }^{3-5}$ Anxiety can severely compromise dental students' performance and general health. ${ }^{6-9}$ Therefore, managing anxiety in dental students has become one of the most important challenges for dental educators. ${ }^{10}$

Throughout the dental education program, dental students must acquire several academic and clinical competencies while improving interpersonal and professionalism skills. ${ }^{6}$ Furthermore, different stages along the program offer different stressors and challenges that may increase the anxiety levels over all years of dental school. ${ }^{5-7}$ Academic factors, such as examinations, grades, and the workload in dental school are the primary source of anxiety and stress among dental students. ${ }^{11}$ Importantly, anxiety among dental students has also been correlated with alcohol abuse and illicit drug usage during undergraduate and dentistry practicing years. ${ }^{12}$

However, although anxious, dental students perceive themselves as positively functioning individuals with high levels of well-being. ${ }^{3,7}$ Well-being has been defined as a positive outcome of people perceiving their lives as going well. ${ }^{13}$ Interestingly, anxiety has been demonstrated to negatively impact well-being and quality of life similarly to medical conditions such as back pain, arthritis, diabetes, and heart disease. ${ }^{13-15}$

The University of Michigan School of Dentistry (UMSOD) has been considered the number one school of dentistry by the Quacquarelli Symonds (QS) in the United States in the past 2 years. ${ }^{16}$ The UMSOD is also at the top of the list of the best dental schools worldwide. ${ }^{16,17}$ Furthermore, in a recent climate survey study at the UMSOD, $65 \%$ of students reported that they experience a humanist environment at school, ${ }^{18}$ which could positively affect UMSOD students' well-being and anxiety levels. Taken together, our goal was to investigate the anxiety and well-being levels of UMSOD students.

We hypothesized that, like other dental students, UMSOD students pose high well-being and suffer from high anxiety. Our study aimed to assess the levels of well-being and anxiety among dental students enrolled at the UMSOD in the academic years 2016 to 2017 and 2017 to 2018. To assess well-being, we used the World Health Organization-Five Well-Being Index (WHO-5) questionnaire. ${ }^{19,20}$ For general anxiety assessment, we used the Generalized Anxiety Disorder 7-item (GAD-7) scale. ${ }^{21-23}$ 
Our rationale for using the WHO-5 and GAD-7 questionnaires was based on the fact that both survey tools are very short and non-invasive, which would allow us to get more responses than using other extensive survey instruments. In addition, the WHO-5 index is the most widely used questionnaire to assess self-reported psychological well-being. The WHO-5 index has adequate validity either as a screening tool for depression or as an outcome measure in clinical trials and in research studies worldwide. ${ }^{19}$ Similarly, the GAD-7 is a self-administered patient questionnaire widely used to screen and measure generalized anxiety disorder. The GAD-7 is very easy to use, and it has been validated within large general population samples and in primary care settings. ${ }^{24}$

\section{Methods}

\section{Study Design and Participants}

This study surveyed all pre-doctoral dental students $(\mathrm{N}=500)$ enrolled at the University of Michigan School of Dentistry during the academic years 2016 to 2017 and 2017 to 2018. Incoming first-year dental students $(\mathrm{N}=109)$ were surveyed in the summer and fall terms of 2017. Recruitment to participate in this study occurred through an invitation email explaining the study procedures and survey tools with a link to answer the surveys through Qualtrics. Subjects who did not answer the year of dental school and/or gender (male, female, and other) were excluded. Once responded, the survey link was closed to the respondent. Participation was voluntary and not compensated. Responses were only identified by gender and year of dental school.

This study was considered exempt and not regulated by the University of Michigan institutional review board under exemption 2 category as a research study involving interview procedures in education settings only.

\section{Data Collection Methods}

The WHO-5 index was used to assess well-being. WHO-5 raw scores vary from 0 to 25 points, 0 being the worst possible well-being and 25 the best. Scores lower than 13 indicate poor well-being, which may require further major depression evaluation. ${ }^{19,20}$ To assess general anxiety we used the GAD-7 index, ${ }^{21-24}$ in which scores vary from 0 to 15 . Scores higher or equal to 10 are considered moderate anxiety, which may indicate a need for further evaluation to confirm the diagnosis. The GAD score 15 is considered a possible indicator of severe anxiety. For this study, we analyzed the percentage of students who scored 10 or higher on the GAD-7 index.

\section{Procedures}

WHO-5 and GAD-7 surveys were sent to all dental students enrolled in the fall term of 2016 and winter term of $2017(\mathrm{~N}=500)$ and to incoming first-year dental students in the June and fall term of $2017(\mathrm{~N}=109)$. The WHO-5 survey was sent in the fall term of 2016 with a follow-up reminder email in the winter term of 2017. The GAD-7 survey was sent in two survey moments, which coincided with the week before and after the spring break week in 2017 . The rationale was to assess the students' perceived anxiety in two distinct moments of the dental school program: before and after a week when there was no academic activity.

For the incoming first-year dental students, the WHO-5 and GAD-7 surveys were sent in June of 2017, before the beginning of the academic activities, and in the fall term of 2017, after 
Table 1. Survey Timeline

\begin{tabular}{|c|c|c|c|}
\hline $\begin{array}{l}\text { Fall } 2016 \\
(\mathrm{~N}=500) \\
\text { All dental } \\
\text { students }\end{array}$ & $\begin{array}{l}\text { Winter } 2017 \\
(\mathrm{~N}=500) \\
\text { All dental } \\
\text { students }\end{array}$ & $\begin{array}{l}\text { Summer } \\
\text { 2017-June } \\
(\mathrm{N}=109) \\
\text { Incoming dental } \\
\text { students }\end{array}$ & $\begin{array}{l}\text { Fall 2017-October } \\
(\mathrm{N}=109) \\
\text { Incoming dental students } \\
\text { after } 3 \text { months into the } \\
\text { dental program }\end{array}$ \\
\hline \multirow[t]{2}{*}{ WHO-5 } & $\begin{array}{l}\text { WHO-5 } \\
\text { survey reminder }\end{array}$ & WHO-5 & WHO-5 \\
\hline & $\begin{array}{l}\text { GAD-7 S1 } \\
\text { (before spring break) } \\
\text { GAD-7 S2 } \\
\text { (after spring break) }\end{array}$ & GAD-7 & GAD-7 \\
\hline
\end{tabular}

3 months of initiated academic activities at the dental school. Our rationale to include incoming first-year dental students was to investigate the beginning of the dental program phase as a potential stressor for dental students. The survey timeline can be seen in Table 1 .

\section{Data Analysis}

We obtained 212 responses on the WHO-5 survey by the end of the winter term of 2017. For the anxiety survey, we obtained 146 (first survey moment; S1) and 109 responses (second survey moment; S2). Among the incoming first-year dental students, we recruited 98 respondents (GAD-7 and WHO-5) in June of 2017 and 53 respondents (GAD-7 and WHO-5) in the fall term of 2017. Female and male dental student responses had similar percentage rates. Approximately 49\% ( $n=303)$ of all the responses from all surveys were from female students and 51\% $(\mathrm{n}=315)$ from male students. Only 1 response had the gender field not selected, and 5 responses did not indicate the year of dental school; these responses were excluded from analysis. For statistical analysis, we use Statistical Product and Service Solutions (SPSS; version 24). Percentages and means were tested using chi-square, and t test were used at $p<0.05$.

\section{Results}

\section{Well-Being Among Dental Students}

There was no significant difference between well-being score means from male and female dental students. However, incoming first-year dental students who had not initiated the dental program presented significantly higher well-being scores than schoolwide dental students (Figure 1a). When analyzed by year of dental school, well-being score mean in incoming first-year dental students was significantly higher than any other group of students analyzed (Figure 1b). The wellbeing scores from male and female incoming first-year dental students were significantly higher than well-being scores from male and female schoolwide dental students (Figure 1c).

We compared the sums of the positive responses in the WHO-5 index from incoming first-year dental students and students schoolwide (Table 2). When compared to other dental students, the higher well-being scores observed among incoming first-year dental students corresponded to the significantly higher ratios of positive responses (scores 3 or higher) on the statement 4 ( $I$ wake up feeling fresh and rested) of the WHO-5 index. Surprisingly, incoming 

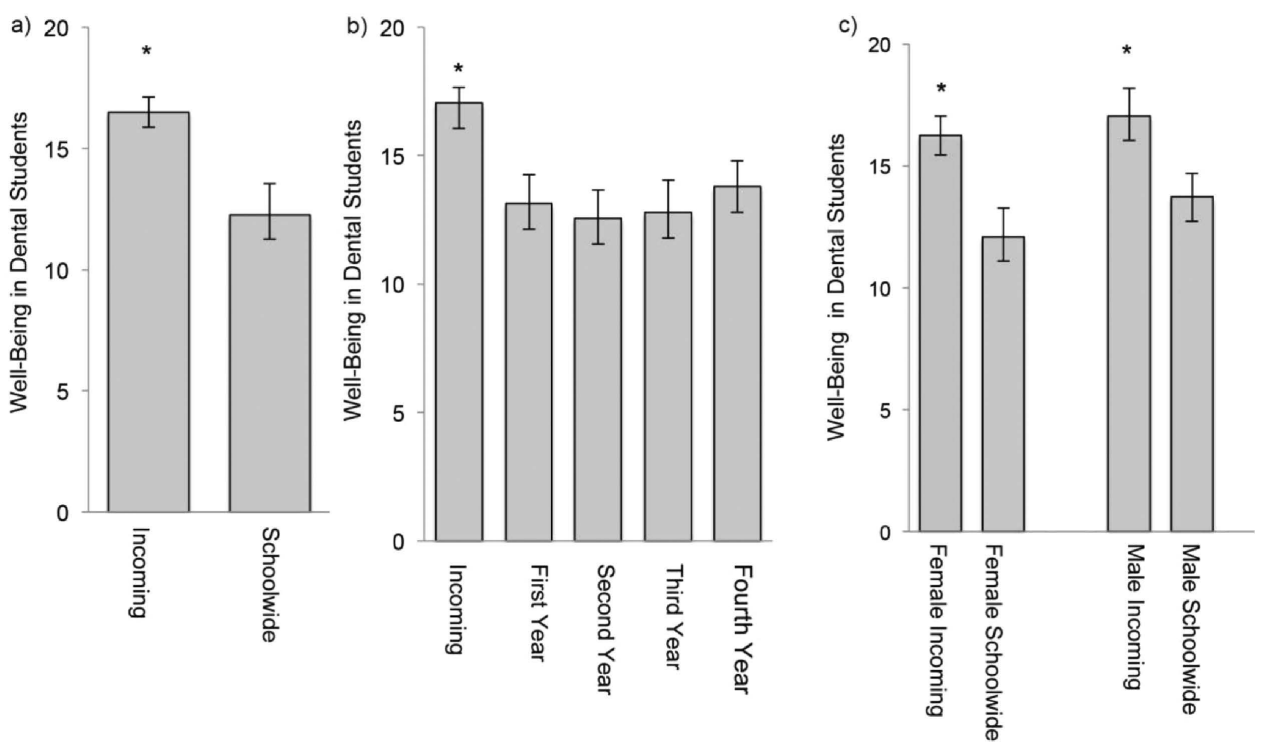

Figure 1. Well-being score means in incoming and schoolwide dental students (a); wellbeing score means by year of dental school (b); well-being score means in female and male dental students (c); statistical significance at $\mathrm{p}<0.0001$.

Table 2. Comparison of the Sum of Positive Responses in the WHO-5 Index: Incoming Dental Students Versus Other Years' Dental Students

\begin{tabular}{|c|c|c|c|c|}
\hline \multirow[t]{2}{*}{ WHO-5 Index } & \multicolumn{4}{|c|}{$\begin{array}{l}\text { Sum of positive responses in the WHO- } 5 \text { Index: Incoming dental } \\
\text { students versus other years' dental students }\end{array}$} \\
\hline & $\begin{array}{l}\text { Incoming } \\
(\mathrm{n}=52) \mathrm{vs} \\
\text { first-year } \\
\text { dental students } \\
(\mathrm{n}=72)\end{array}$ & $\begin{array}{l}\text { Incoming } \\
(\mathrm{n}=52) \mathrm{vs} \\
\text { second-year } \\
\text { dental students } \\
(\mathrm{n}=49)\end{array}$ & $\begin{array}{l}\text { Incoming } \\
(\mathrm{n}=52) \mathrm{vs} \\
\text { third-year } \\
\text { dental students } \\
(\mathrm{n}=51)\end{array}$ & $\begin{array}{l}\text { Incoming vs } \\
(\mathrm{n}=52) \\
\text { fourth-year } \\
\text { dental students } \\
(\mathrm{n}=45)\end{array}$ \\
\hline $\begin{array}{l}\text { 1. I have felt cheerful } \\
\text { and in good spirits }\end{array}$ & 1.25 & 1.38 & 1.44 & 1.129 \\
\hline $\begin{array}{l}\text { 2. I have felt calm } \\
\text { and relaxed }\end{array}$ & 1.57 & 1.844 & 1.804 & 1.27 \\
\hline $\begin{array}{l}\text { 3. I have felt active } \\
\text { and vigorous }\end{array}$ & 1.61 & 1.74 & 1.74 & 1.07 \\
\hline $\begin{array}{l}\text { 4. I wake up feeling } \\
\text { fresh and rested }\end{array}$ & $3.512^{* * *}$ & $3.512^{* * *}$ & $3.10^{* * *}$ & 1.67 \\
\hline $\begin{array}{l}5 . \text { My daily life has } \\
\text { been filled with things } \\
\text { that interest me }\end{array}$ & 1.54 & 1.47 & 1.44 & 1.22 \\
\hline
\end{tabular}

"Positive responses include the responses all of the time (score $=5)$, most of the time (score $=4)$, and more than half of the time (score $=3$ ). The WHO-5 Index is available in the Appendix section.

Significant at $\mathrm{p}<0.0001$. 

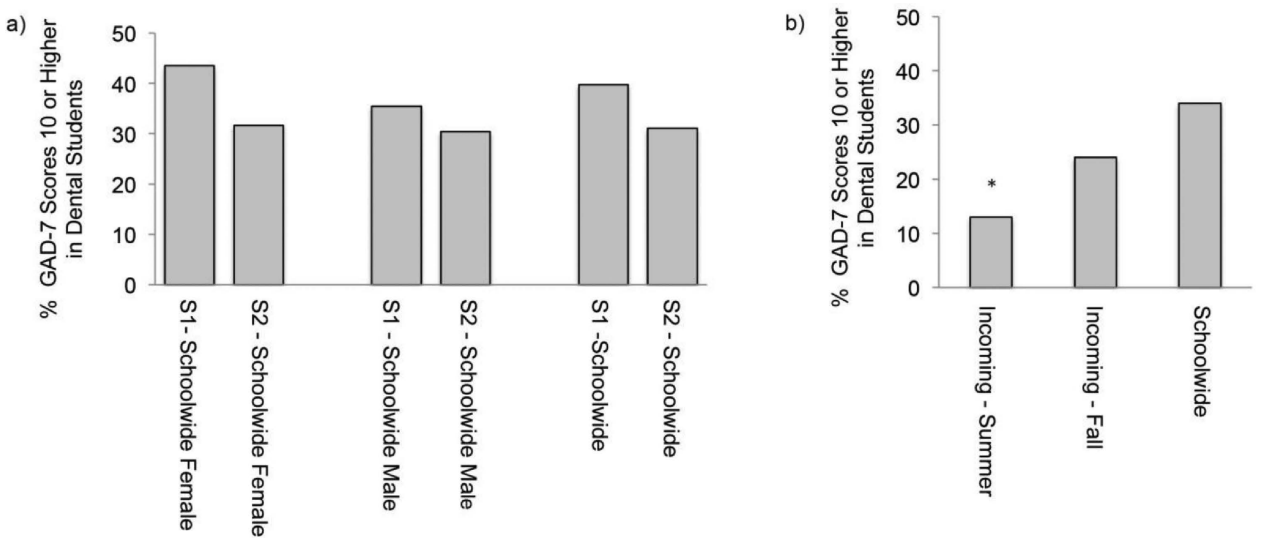

Figure 2. Percentage of female and male students with GAD-7 scores 10 or higher in surveys 1 and 2 (S1, S2) (a); percentage of dental students with GAD-7 scores 10 or higher (b); statistical significance at $\mathrm{p}=0.0046$.

first-year dental students obtained higher ratios of positive responses in all 5 statements of the WHO-5 index when compared to all other dental students in all 4 years of dental school (Table 2).

\section{Anxiety Among Dental Students}

In the first anxiety survey moment (S1), before the spring break week, approximately $40 \%$ $(n=58)$ of all respondents scored 10 or higher in the GAD-7 survey. In the second anxiety survey moment (S2), after the spring break week, the percentage of students with GAD-7 scores 10 or higher dropped to approximately $32 \%(\mathrm{n}=34)$. There was no significant difference in overall anxiety scores in S1 and S2 or between female and male students' anxiety scores (Figure 2a).

When the GAD-7 scores of female and male incoming first-year dental students and schoolwide dental students were analyzed, significantly lower percentages of GAD-7 scores 10 or higher were observed in incoming first-year dental students. However, when incoming first-year dental students' anxiety levels were assessed during the fall term of 2017, 3 months after initiating the dental school academic activities, their anxiety scores were similar to the schoolwide levels (Figure 2b).

\section{Discussion}

The goal of this study was to assess the well-being and general anxiety levels of UMSOD students. We hypothesized that UMSOD students posed high levels of both well-being and anxiety. Our hypothesis was partially supported by our results, which showed that a high percentage of the University of Michigan dental students had GAD-7 scores 10 or higher in both anxiety survey moments. However, contrary to what we had hypothesized, UMSOD dental students scored low levels of well-being, which are similar to the low levels of well-being self-reported by practicing dentists. ${ }^{25}$ Surprisingly, incoming first-year dental students reported normal wellbeing levels before starting the dental school program at the UMSOD; self-reported well-being dropped significantly in the following 3 months over the fall term.

In both survey moments, more than $30 \%$ of all students had GAD-7 scores indicative of moderate to severe anxiety, which is a higher percentage than previously reported in other 
studies. ${ }^{26,27}$ Interestingly, incoming first-year dental students reported significantly higher levels of well-being and lower levels of anxiety before starting the dental program. After 3 months of the initiation of the UMSOD dental program, incoming first-year dental students reported similar well-being scores as the first-year dental students surveyed in 2017 (data not shown). Additionally, the percentage of incoming first-year dental students with scores 10 or higher in the GAD-7 increased over the same period and is comparable to schoolwide students' anxiety levels during the same term.

Our study had important limitations. The short survey tools used in this study are applicable in general populations. However, our studied population of only dental students may differ from other populations. Furthermore, the study used survey tools that do not allow a final diagnosis of either depression (WHO-5) or anxiety disorder (GAD-7) even in situations of very low well-being scores and/or high anxiety scores. In addition, because the participation in this study was voluntary, the percentage of responses decreased as the multiple surveys were sent. Another important limitation of our study is that incoming first-year dental students were first surveyed during the summer (June of 2017) before the beginning of the academic year, which may have contributed to the greater number of responses reporting higher levels of well-being and lower levels of anxiety. Additionally, it is possible that throughout the academic year, as the stressors emerged, the most anxious students could have answered the surveys more frequently, which might have created a respondent bias.

Dental students often pose high levels of self-reported anxiety during their dental education program. ${ }^{28}$ Anxiety among dental students, as in other populations, also compromises academic performance and students' overall health. ${ }^{8,28}$ Consequently, dental students' anxiety has become a major concern for dental educators. ${ }^{10-12}$ Surprisingly, well-being is generally found to be high among dental students. ${ }^{3,7}$ However, in our study, we found that UMSOD students have high levels of anxiety and also pose low well-being levels, which seems to be a very particular characteristic of UMSOD students. ${ }^{4,7,29}$ Our findings suggest that UMSOD students may need additional psychological support to address anxiety and well-being throughout all years of dental school.

Studies have found that dental students' perceived stress corresponds to the transition from didactic to pre-clinical and clinical phases of the dental school curriculum. ${ }^{30,31}$ Stressors such as pressure to perform, workload, and perceptions of self-efficacy have been the most common self-reported stressors among dental students. ${ }^{4,5,32}$ Interestingly, our results suggest that the 3-month transition phase to dental school may be an important stressor to dental students. The impact of this transition to the dental school program on dental students' anxiety and wellbeing has never been investigated. Consequently, future studies are necessary to investigate the first trimester of dental school in dental students' overall wellness.

\section{Conclusion}

Well-being scores were normal for incoming first-year students before starting dental school and decreased after the first trimester of dental school. This decrease in well-being scores indicates that the first trimester of dental school program may represent an important stressor with a potential to reduce well-being levels. In addition, after 3 months of dental school, the anxiety levels reported from the incoming first-year dental students were similar to schoolwide students, which is consistent with the drop of well-being levels observed by the same group in the same period. Future studies are necessary to investigate the impact of the first trimester of dental school in dental students' psychological and overall health. 
Identifying the dental education program challenges and their impact on dental students' well-being and anxiety levels could facilitate stress and anxiety management as the students face different phases during the program. Despite the limitations of our study, it brings up the need to assess the overall quality of life of dental students, particularly in the first trimester of the dental school program. Hopefully, this study facilitates future research to investigate the use of feasible approaches to improve dental students' wellness throughout their dental education.

\section{Acknowledgments}

I would like to thank the University of Michigan dental students for their participation in this study and Dr. Karl for her guidance through the completion of this project.

\section{References}

1. Craske MG, Stein MB. Anxiety. Lancet. 2016;388(10063):3048-3059. doi:10.1016/ S0140-6736(16)30381-6

2. Bystritsky A, Khalsa SS, Cameron ME, Schiffman J. Current diagnosis and treatment of anxiety disorders. P T. 2013;38(1):30-57.

3. Harris M, Wilson JC, Holmes S, Radford DR. Perceived stress and well-being among dental hygiene and dental therapy students. Br Dent J.2017;222(2):101-106. doi:10.1038/ sj.bdj. 2017.76

4. Barbería E, Fernández-Frías C, Suárez-Clúa C, Saavedra D. Analysis of anxiety variables in dental students. Int Dent J. 2004;54(6):445-449. doi:10.1111/j.1875-595x.2004.tb00302.x

5. Polychronopoulou A, Divaris K. Dental students' perceived sources of stress: a multi-country study.J Dent Educ. 2009;73(5):631-639. doi:10.1002/j.0022-0337.2009.73.5.tb04738.x

6. Basudan S, Binanzan N, Alhassan A. Depression, anxiety and stress in dental students. Int J Med Educ. 2017;8:179-186. doi:10.5116/ijme.5910.b961

7. Preoteasa CT, Mircescu G, Buzea MC, Preoteasa E. Sources of stress and well-being in dental students. Rom J Oral Rehab. 2015;7(1):28-32.

8. Farrelly C, Sun J, Mack F. Impact of stress on depression and anxiety in dental students and professionals. Int Public Health J. 2013;5(4):485-498.

9. Kirova DG. Dental anxiety among dental students. J of IMAB. 2011;17(2):137-139. doi:10.5272/ jimab.2011172.137

10. Murphy RJ, Gray SA, Sterling G, Reeves K, DuCette J. A comparative study of professional student stress.J Dent Educ. 2009;73(3):328-337. doi:10.1002/j.0022-0337.2009.73.3.tb04705.x

11. Elani HW, Allison PJ, Kumar RA, Mancini L, Lambrou A, Bedos C.

A systematic review of stress in dental students. J Dent Educ. 2014;78(2):226-242.

doi:10.1002/j.0022-0337.2014.78.2.tb05673.x

12. Newbury-Birch D, Lowry RJ, Kamali F. The changing patterns of drinking, illicit drug use, stress, anxiety and depression in dental students in a UK dental school: a longitudinal study. Br Dent J. 2002;192(11):646-649. doi:10.1038/sj.bdj.4801448

13. de Beurs E, Beekman AT, van Balkom AJ, Deeg DJ, van Dyck R, van Tilburg W. Consequences of anxiety in older persons: its effect on disability, well-being and use of health services. Psychol Med.1999;29(3):583-593. doi:10.1017/s0033291799008351

14. Schonfeld WH, Verboncoeur CJ, Fifer SK, Lipschutz RC, Lubeck DP, Buesching DP. The functioning and well-being of patients with unrecognized anxiety disorders and major depressive disorder.J Affect Disord. 1997;43(2):105-119. doi:10.1016/s0165-0327(96)01416-4

15. Diener E, Napa Scollon C, Lucas RE. The evolving concept of subjective well-being: the multifaceted nature of happiness. In: Diener E, ed. Assessing Well-Being. Springer; 2009:67-100. Michalos AC, ed. Social Indicators Research Series; vol 39. 
16. Jöns H, Hoyler M. Global geographies of higher education: the perspective of world university rankings. Geoforum. 2013;46:45-59. doi:10.1016/j.geoforum.2012.12.014

17. QS Top Universities. Dentistry. Accessed May 31,2019. https://www.topuniversities.com/ university-rankings/university-subject-rankings/2019/dentistry

18. Curtis Center Program Evaluation Group. University of Michigan School of Dentistry Climate Study: Final Report. University of Michigan School of Social Work; 2015. Accessed May 31, 2019. http://media.dent.umich.edu/planning/files/UMSDClimateStudyFinalReport.pdf

19. Topp CW, Østergaard SD, Søndergaard S, Bech P. The WHO-5 well-being index: a systematic review of the literature. Psychother Psychosom. 2015;84(3):167-176. doi:10.1159/000376585

20. Bech P, Olsen LR, Kjoller M, Rasmussen NK. Measuring well-being rather than the absence of distress symptoms: a comparison of the SF-36 mental health subscale and the WHO-Five well-being scale. Int J Methods Psychiatr Res. 2003;12(2):85-91. doi:10.1002/mpr.145

21. Stein MB, Sareen J. Generalized anxiety disorder. N Engl J Med. 2015;373(21):2059-2068. doi:10.1056/NEJMcp1502514

22. Löwe B, Decker O, Müller S, et al. Validation and standardization of the Generalized Anxiety Disorder Screener (GAD-7) in the general population. Med Care. 2008;46(3):266-274. doi:10.1097/MLR.0b013e318160d093

23. Spitzer RL, Kroenke K, Williams JBW, Löwe B. A brief measure for assessing generalized anxiety disorder: the GAD-7. Arch Intern Med. 2006;166(10):1092-1097. doi:10.1001/ archinte.166.10.1092

24. Jordan P, Shedden-Mora MC, Löwe B. Psychometric analysis of the Generalized Anxiety Disorder scale (GAD-7) in primary care using modern item response theory. PLoS One. 2017;12(8):e0182162. doi:10.1371/journal.pone.0182162

25. Collin V, Toon M, O'Selmo E, Reynolds L, Whitehead P. A survey of stress, burnout and wellbeing in UK dentists. Br Dent J. 2019;226(1):40-49. doi:10.1038/sj.bdj.2019.6

26. Knipe D, Maughan C, Gilbert J, Dymock D, Moran P, Gunnell D. Mental health in medical, dentistry and veterinary students: cross-sectional online survey. BJPsych Open. 2018;4(6):441-446. doi:Io.II92/bjo.2oI8.6I

27. Musumari PM, Tangmunkongvorakul A, Srithanaviboonchai K, et al. Grit is associated with lower level of depression and anxiety among university students in Chiang Mai, Thailand: a crosssectional study. PLoS One. 2018;13(12):e0209121. doi:10.1371/journal.pone.0209121

28. Alzahem M, van der Molen HT, Alaujan AH, Schmidt HG, Zamakhshary MH. Stress amongst dental students: a systematic review. Eur J Dent Educ. 2011;15(1):8-18. doi:10.1111/j.1600-0579.2010.00640.x

29. Harris M, Wilson JC, Holmes S, Radford DR. Perceived stress and well-being among dental hygiene and dental therapy students. Br Dent J. 2017;222(2):101-106. doi:10.1038/sj.bdj.2017.76

30. Polychronopoulou A, Divaris K. A longitudinal study of Greek dental students' perceived sources of stress. J Dent Educ. 2010;74(5):524-530. doi:10.1002/j.0022-0337.2010.74.5.tb04899.x

31. Frese C, Wolff D, Saure D, Staehle HJ, Schulte A. Psychosocial impact, perceived stress and learning effect in undergraduate dental students during transition from pre-clinical to clinical education. Eur J Dent Educ. 2018;22(3):e555-e563. doi:10.1111/eje.12352

32. Uraz A, Tocak YS, Yozgatligil C, Cetiner S, Bal B. Psychological well-being, health and stress sources in Turkish dental students. J Dent Educ. 2013;77(10):1345-1355. doi:10.100 2/j.0022-0337.2013.77.10.tb05609.x 


\section{Appendix}

GAD-7: The Generalized Anxiety Disorder 7-Item Scale

\begin{tabular}{|l|c|c|c|c|}
\hline $\begin{array}{l}\text { Over the last } 2 \text { weeks, how } \\
\text { often have you been bothered } \\
\text { by the following problems? }\end{array}$ & Not at all & Several days & $\begin{array}{c}\text { More than } \\
\text { half the days }\end{array}$ & $\begin{array}{c}\text { Nearly every } \\
\text { day }\end{array}$ \\
\hline $\begin{array}{l}\text { 1. Feeling nervous, anxious, } \\
\text { or on edge }\end{array}$ & 0 & 1 & 2 & 3 \\
\hline $\begin{array}{l}\text { 2. Not being able to stop or } \\
\text { control worrying }\end{array}$ & 0 & 1 & 2 & 3 \\
\hline $\begin{array}{l}\text { 3. Worrying too much about } \\
\text { different things }\end{array}$ & 0 & 1 & 2 & 3 \\
\hline $\begin{array}{l}\text { 4. Trouble relaxing } \\
\text { 5. Being so restless that it is } \\
\text { hard to sit still }\end{array}$ & 0 & 1 & 2 & 3 \\
\hline $\begin{array}{l}\text { 6. Becoming easily annoyed } \\
\text { or irritable }\end{array}$ & 0 & 1 & 2 & 3 \\
\hline $\begin{array}{l}\text { 7. Feeling afraid as if some- } \\
\text { thing awful might happen }\end{array}$ & 0 & 1 & 2 & 3 \\
\hline
\end{tabular}

WHO-5: Well-Being Index

\begin{tabular}{|l|c|c|c|c|c|c|}
\hline Over the last 2 weeks & $\begin{array}{c}\text { All the } \\
\text { time }\end{array}$ & $\begin{array}{c}\text { Most of } \\
\text { the time }\end{array}$ & $\begin{array}{c}\text { More } \\
\text { than } \\
\text { half the } \\
\text { days }\end{array}$ & $\begin{array}{c}\text { Less } \\
\text { than } \\
\text { half of } \\
\text { the time }\end{array}$ & $\begin{array}{c}\text { Some of } \\
\text { the time }\end{array}$ & $\begin{array}{c}\text { At no } \\
\text { time }\end{array}$ \\
\hline $\begin{array}{l}\text { 1. I have felt cheerful and in } \\
\text { good spirits }\end{array}$ & 5 & 4 & 3 & 2 & 1 & 0 \\
\hline 2. I have felt calm and relaxed & 5 & 4 & 3 & 2 & 1 & 0 \\
\hline $\begin{array}{l}\text { 3. I have felt active and } \\
\text { vigorous }\end{array}$ & 5 & 4 & 3 & 2 & 1 & 0 \\
\hline $\begin{array}{l}\text { 4. I wake up feeling fresh and } \\
\text { rested }\end{array}$ & 5 & 4 & 3 & 2 & 1 & 0 \\
\hline $\begin{array}{l}\text { 5. My daily life has been filled } \\
\text { with things that interest me }\end{array}$ & 5 & 4 & 3 & 2 & 1 & 0 \\
\hline
\end{tabular}

(C) 2021 Author(s)

This is an open-access article distributed under the terms of the Creative Commons Attribution 4.0 International license, which permits anyone to download, copy, distribute, display, or adapt the text without asking for permission, provided that the creator(s) are given full credit. 